\title{
Ilustración, nación e imperio en la monarquía española ${ }^{1}$
}

\section{Enlightenment, Nation and Empire in the Spanish Monarchy}

\author{
José M. Portillo Valdés ${ }^{2}$ \\ Universidad del País Vasco (España)
}

Recibido: $30-06-18$

Aprobado: 28-07-18

\section{Resumen}

Este ensayo parte de una consideración crítica de la relación entre cosmopolitismo y "nacionalismo" en el pensamiento ilustrado. A partir de ahí llama la atención sobre algunas cuestiones que caracterizaron el pensamiento "nacional" de la Ilustración en la monarquía española. Por una parte su inserción en el espacio de civilización europeo $\mathrm{y}$, por otra, su propia condición imperial.

Palabras-clave: Ilustración española, imperio, nación, cultura española.

\begin{abstract}
From a critical perspective of the relationship between cosmopolitism and nationalism in the Enlightenment, this article considers two characteristics of the Spanish enelightened thought. On the one hand the insertion of Spain and its culture in the mainstream of the European civilization. On the other hand the intepretation of the "Spanish nation" in an imperial context.

Key-words: Spanish Enlightenment, Empire, Nation, Spanish Culture.

\footnotetext{
${ }^{1}$ Una versión más reducida de este texto se publicó en Revista de Occidente, 445, 2018.

2 (josemaria.portillo@ehu.eus) Catedrático de Historia Contemporánea de la Universidad del País Vasco. Ha sido profesor en las universidades de Georgetown y Nevada en EEUU, de El Colegio de México y el Instituto Mora en México, de la Universidad Externado de Colombia y de la de Santiago de Compostela. Entre sus publicaciones recientes: Entre tiros e Historia. La constitución de la autonomía vasca, 1976-1979, Barcelona, Galaxia Gutenberg, 2018; Historia Minima del Constitucionalismo en América Latina, El Colegio de México, México, 2015 y Fuero Indio. La provincia de Tlaxcala entre la monarquía imperial y la república nacional, 1787-1824, México, El colegio de México, 2014.
} 
Cuando Kant elaboró definitivamente su teoría del juicio a finales del siglo XVIII, asentó la relevancia de la distinción entre juicio privado y público. Este segundo, en el que realmente se mostraba la autonomía individual, debía producirse en un espacio de libertad entre iguales donde era posible generar una opinión pública. Ese era el fundamento para Kant de un gobierno justo y constitucional porque establecía una identidad entre los individuos autónomos, responsables e ilustrados y el gobierno. Como es sabido, Kant, en realidad, pensaba en ese como el fundamento de una suerte de gobierno universal de la humanidad, pues los principios esenciales que debían guiar el juicio de los hombres no eran más que los universales y naturales deducibles por la razón ${ }^{3}$.

Ese rasgo universal del pensamiento es algo bastante común a los protagonistas de la Ilustración. No en vano fue un movimiento que quiso tener siempre como horizonte propio la república de las letras. Transfronteriza desde sus primeras idealizaciones, esa república era concebida como un espacio de pensamiento liberado de los constreñimientos de las repúblicas políticas, de las soberanías monárquicas o de otro tipo que interferían en el mismo. Como superación del Parnaso literario, la república de las letras era un espacio donde no solamente los poetas sino todos los "hombres de letras" podían encontrarse más allá de las fronteras que sus respectivos soberanos asignaban a sus Estados ${ }^{4}$.

Sin embargo, es preciso recordar también que los espacios públicos en los que ese ideal podía tomar cuerpo no surgían de manera espontánea sino que eran deliberadamente construidos. Podían tomar formas diversas (academias, tertulias, salones y, sobre todo, revistas), obedeciendo a estrategias y objetivos que la historiografía ha ido conociendo mejor en las últimas décadas ${ }^{5}$. Esos espacios, que sí tenían concreción física, respondían a requerimientos por un lado universales, como la propia república de las letras, pero, por otro lado, obedecían también sin duda a exigencias "nacionales". Es ese un rasgo que desde sus mismos orígenes marca también a la Ilustración, pues en la república de las letras no dejó nunca de practicarse la emulación nacional.

En cierto modo, desde entonces la tradición historiográfica sobre ese fenómeno que tuvo tantas ansias de universalizar no solo el conocimiento sino el juicio, ha corrido más bien pareja a las experiencias nacionales. Al fin y al cabo, al mismo Kant se le estudia bajo el epígrafe de la ilustración alemana, lo mismo que se identifica otra escocesa, napolitana o francesa. No se trata aquí de abrir cuestión sobre la idoneidad de una aproximación nacional a la Ilustración, sino más bien de constatar que ante todo parece inevitable ${ }^{6}$. No

\footnotetext{
${ }^{3}$ Reidar Maliks, Kant's Politics in Context, Oxford, OUP, 2014 cap. 1.

${ }^{4}$ Joaquín Álvarez Barrientos, François Lope e Inmaculada Urzainqui, La república de las letras en la España del siglo XVIII, Madrid, CSIC, 1995.

${ }_{5}^{5}$ Brad Panasek y Chad Wellmon, "Enlightenment, Some Assembly Required" en David T. Gies y Cynthia Wall (eds), The Eighteenth Century. Global Networks of Enlightenment, Charlotesville, University of Virginia Press, 2018.

${ }^{6}$ El conocido L'Illuminismo. Dizionario storico, Roma, Laterza, 1998 dirigido por Vicenzo
} 
solamente porque nuestra cultura, y por ende nuestra cultura historiográfica contemporánea, está tallada sobre el molde del principio de nacionalidad sino porque el propio pensamiento ilustrado propició esa aproximación. En efecto, si, por una parte, la Ilustración promovió la idea de la universalidad de la razón, por otro lado no dejó de mostrar una creciente preocupación por diferenciar espacios "nacionales" dentro de la república de las letras.

Creo que el dato se muestra más interesante si tenemos presente que justamente será desde una perspectiva de lo «nacional» que, comenzando por Johann Gottfried Herder y siguiendo por los críticos de la revolución francesa, se cuestionará el pensamiento cosmopolita de la Ilustración. Es quizá esa crítica, que acabaría en algunos casos promoviendo un pensamiento anti-moderno, la que también contribuyó más a estereotipar la Ilustración como un fenómenos universalista y al margen del nacionalismo que, en el siglo XIX, se adueñaría del hemisferio occidental ${ }^{7}$.

El condicionante nacional de la Ilustración debe, no obstante, tenerse presente para comprender la relación entre ese pensamiento y un espacio tan característico como el de la monarquía hispana. En primer lugar por el hecho de que fue precisamente el pensamiento ilustrado el que sometió a una crítica más sistemática lo que entendía fundamentos periclitados de los extensos dominios que aún conservaba dicha monarquía. Como es bien sabido, ello dio lugar a una de las polémicas más "nacionales" que entretuvieron al pensamiento europeo de las décadas finales del setecientos ${ }^{8}$. Pero también porque esa misma disputa "nacional" se reprodujo al interior del espacio hispano.

Debe aquí tomarse el término nacional en el sentido que cobró entonces, esto es, como una forma de identidad literaria, de reconocimiento de una comunidad de escritores que ensalzaban - cuando tocaba- las glorias propias o cuestionaban las ajenas. Nacional era también el carácter, es decir, las particularidades que derivaban de condiciones ambientales, culturales e históricas de las gentes de un reino y que influían poderosamente en su forma política y en su legislación. Nacional, decía entonces el diccionario de la Real Academia, es lo que es propio de una nación, o es natural de ella, es decir, de la "colección de habitantes", que es como se define a su vez la nación.

Los debates ilustrados sobre España y sobre su significación para la civilización europea se enmarcaron en esas coordenadas. El cuestionamiento abierto de la pertenencia incluso de España y los españoles a un espacio literario europeo, generó, como ha estudiado bien la historiografía, un

Ferrone y Daniel Roche, aun presentando preferentemente un carácter universal en el tratamiento de cuestiones de la Ilustración, no puede finalmente resistir la regionalización nacional del movimiento.

7 Zeev Sternhell, The Anti-Enlightenment Tradition, New HAven, Yale UP, 2010 cap. 6. Antoine Compagnon, Los antimodernos, Barcelona, Acantilado, 2007.

${ }^{8}$ Anotnello Gerbi, La disputa del Nuevo Mundo. Historia de una polémica, 1750-1900, México, FCE, 1993; Jorge Cañizares-Esguerra, Cómo escribir la historia del Nuevo Mundo. Historiografias, epistemologías e identidades en el mundo del Atlántico del siglo XVIII, México, FCE, 2007.

Araucaria. Revista Iberoamericana de Filosofia, Política, Humanidades y Relaciones Internacionales, año 20, ${ }^{\circ} 40$. Segundo semestre de 2018. Pp. 59-73. ISSN 1575-6823 e-ISSN 2340-2199 doi: 10.12795/araucaria.2018.i40.03 
estímulo para el pensamiento español de las décadas finales del siglo XVIII. Lo fue, desde luego, para aquellas formas de pensamiento que adquirieron un sesgo más "nacional" y que debatieron sobre el lugar propio de la cultura española en el escenario de la república de las letras europea. Estudios sobre las publicaciones periódicas en la España de finales del setecientos han descrito bien esa generación de espacios para la exaltación de glorias literarias nacionales en un contexto de vindicación de la regularidad civilizadora española en Europa'.

No fueron, sin embargo, solamente los autores que "vindicaron" a España quienes adoptaron la perspectiva nacional al entrar en algunas cuestiones relevantes. También quienes se aproximaron entonces con nuevos métodos al derecho, la geografía o la historia encontraron una muy apropiada aproximación a su objeto de estudio desde una idea de "nación española". Es bien sabido, por ejemplo, el tratamiento preferente que los juristas del momento dieron al "derecho patrio", significando con ello el derecho derivado de fuentes autóctonas frente al preponderante derecho romano. Como ha explicado la historiografía jurídica, lo relevante no es tanto determinar qué era y qué no derecho romano en una cultura de Ius commune, sino que se considerara "patrio" y autóctono un derecho medieval ${ }^{10}$. De este modo, si, por un lado, aquel pensamiento mostraba una vocación universalista en el sentido de procurar colocar a España y su cultura en un mainstream europeo, por otro no pudo mostrarse más entusiasta de lo español cuando se trataba de reclamar su condición de cultura esencial de la civilización europea.

Este cruce fue especialmente significativo para el pensamiento español de finales del siglo XVIII porque fue entonces también cuando, de una manera más decidida, la monarquía católica buscó configurarse como un imperio. Como ha venido mostrando recientemente la historiografía, fue a partir de la constatación de la vulnerabilidad de la monarquía en la guerra de los Siete Años — a la que la monarquía española entró prácticamente solo para perderla—que los teóricos y prácticos de la monarquía (muchas veces los mismos, como Campomanes) comenzaron a pensar en términos imperiales ${ }^{11}$. Se rescataron para ello textos e

\footnotetext{
9 Francisco Sánchez-Blanco, Europa y el pensamiento español del siglo XVIII, Madrid, Alianza, 1991; Siegfried Jüttner, "Archive der Nationenbildung im Namen Europas. Die Presse im Spanien der Aufklärung als Medium nationaler Regeneration”, en Siegfried Jüttner, Die Konstituierung eines Kultur- und Kommunikationsraumes Europa im Wandel der Medienlandschaft des 18. Jahrhunderts, Berlín, Peter Lang, 2008.

10 Jesús Vallejo, "El Fuero Real bajo las luces, o las sombras de la edición de 1781", en Initium. Revista Catalana d'Història del Dret, 1, 1996 y "De sagrado arcano a constitución esencial. Identificación histórica del derecho patrio" en Pablo Fernández Albaladejo (ed.), Los Borbones. Dinastía y memoria de nación en la España del siglo XVIII, Madrid, Marcial Pons - Casa de Velázquez, 2001; Esteban Conde, Medioevo ilustrado. La edición erudita del Ordenamiento de Alcalá (1774), Sevilla, Secretariado de Publicaciones de la Universidad de Sevilla, 1998.

11 José Fidel Tavárez, "La invención de un imperio comercial hispano, 1740-1765", Magallánica, 2/3, 2015 .
}

Araucaria. Revista Iberoamericana de Filosofía, Política, Humanidades y Relaciones Internacionales, año 20, $\mathrm{n}^{\circ} 40$ Segundo semestre de 2018. Pp. 59-73. ISSN 1575-6823 e-ISSN 2340-2199 doi: 10.12795/araucaria.2018.i40.03 
ideas que se habían formulado antes, incluso con notable precisión, sobre todo en el reinado de Fernando VI que ponían la mira en el modelo que había seguido el principal competidor imperial, Inglaterra, y aquellos que habían logrado consolidar un comercio imperial, incluso no teniendo una gran significación como potencia europea, como Holanda ${ }^{12}$.

Como es bien sabido, desde el final de aquella especie de primera guerra mundial, la monarquía comenzó a ensayar nuevas formas de gobierno en América que buscaban superar los modelos derivados de la planta virreinal tradicional. No es algo peculiar de esta monarquía, puesto que las dimensiones de aquel conflicto no solamente cambiaron la forma de hacer la guerra, sino, sobre todo, la manera en que las monarquías europeas tuvieron que afrontar su financiación y organización ${ }^{13}$. En la monarquía española, sin embargo, el final de dicha guerra, habiendo entrado tarde y básicamente para perderla, tuvo como punto de partida para la reflexión imperial el hecho de que por primera vez, con la toma de La Habana y Manila, el imperio se mostraba claramente vulnerable. Fueron estas circunstancias las que de manera más relevante espolearon los proyectos de reforma militar y de gobierno imperial ${ }^{14}$.

El ejemplo más acabado de esta nueva concepción imperial de la monarquía fue, sin duda, el ideado por José de Gálvez para la Nueva España en 1786 y que entraría en vigor al año siguiente. Deliberadamente, en su primera versión luego fuertemente corregida, buscaba implantar gobiernos pretorianos que vincularan lo más directamente posible a los territorios, las gentes y, sobre todo, los recursos con los intereses imperiales de la monarquía española. Todo ello, en la mente imperial de Gálvez, debía pivotar sobre un sistema imperial concebido a base de provincias (en su más literal sentido, como territorios anexados a un imperio) gobernadas por militares en quienes se concentrarían todos los poderes (las cuatro causas: hacienda, guerra, justicia y policía o gobierno interior $)^{15}$.

El tono imperial venía marcado también por la sustitución de los corregidores y alcaldes mayores por subdelegados, dependientes incluso en su nombramiento de los intendentes, y por la imposibilidad de que estos crearan corte propia mediante un sistema de movilidad. Para su primera experiencia en el gobierno de intendencias del imperio, Gálvez contó con un cuerpo de

\footnotetext{
${ }_{12}$ Josep M. Delgado, Dinámicas imperiales. España, América y Europa en el cambio institucional del sistema colonial español, Barcelona, Bellaterra, 2007.

${ }^{13}$ David A. Bell, The First Total War. Napoleon's Europe and the Birth of Warfare as we know it, Nueva York, Mariner Books, 2008.

${ }^{14}$ Stanley J. Y Barbara Stein, Apogee of empire : Spain and New Spain in the age of Charles III, 1759-1789, Baltimore, Johns Hopkins UP, 2003; Rafael Torres, El precio de la guerra. El estado fiscal-militar de Carlos III (1779-1783), Madrid, Marcial Pons, 2013; Alan Kuethe y Keneth J. Adrien (eds), The Spanish Atlantic World in the eighteenth Century: War and the Bourbon Reforms, 17131796, Cambridge, Cambridge UP, 2014.

${ }^{15}$ Rafael Diego-Fernández, El proyecto de José Gálvez de 1774 en las Ordenanzas de Intendentes de Río de la Plata y Nueva España, Zamora, El Colegio de Michoacán, 2016.
}

Araucaria. Revista Iberoamericana de Filosofia, Política, Humanidades y Relaciones Internacionales, año $20, \mathrm{n}^{\circ} 40$. Segundo semestre de 2018. Pp. 59-73. ISSN 1575-6823 e-ISSN 2340-2199 doi: 10.12795/araucaria.2018.i40.03 
servidores de la monarquía que habían acompañado al ministro desde sus inicios aquellos proyectos y que compartían la visión imperial del malagueño ${ }^{16}$.

Con todo y sus correcciones, la Ordenanza que llegó a Nueva España para implementar el nuevo gobierno era una forma de concebir la monarquía que, a juicio de algunos historiadores de la economía, logró una notable efectividad hacia el final del reinado de Carlos III $^{17}$. Efectividad aquí quiere decir que México se había logrado establecer como una suerte de submetrópoli de todo el área circuncaribeña y novohispana siendo capaz de sostener financieramente el imperio en todo el área centro y norteamericana. También que un nuevo sistema de consulados de comercio y la decisión previa de abrir el circuito a todos los puertos peninsulares (excepto los vascos) en 1778 permitían pensar en la posibilidad de un sistema más integrado del que forma parte también la concepción de una defensa imperial del imperio a través de nuevas fortificaciones y de un sistema de milicias. Efectividad también quería decir una creciente capacidad de las oficinas imperiales para esquilmar los bienes en manos de aquellos súbditos más vulnerables al nuevo sistema, como las comunidades indígenas, sin por ello poner en cuestión el orden social que la misma fiscalidad permite ver preservado $^{18}$.

Es bien cierto que ese replanteamiento imperial de la monarquía católica no aguantó la prueba de fuerza a que la sometió inmediatamente la tectónica imperial atlántica. A la altura del final del reinado de Carlos III (1788), parecía que las piezas se habían reajustado de manera mínimamente coherente y se había conseguido establecer un flujo de recursos fiscales que avalaban el proyecto de imperialización de la monarquía, culminando otro de integración económica y comercial interna en diferentes áreas ${ }^{19}$. Poco después, sin embargo, comenzaron a notarse cada vez más determinantemente los efectos tanto de la crisis imperial británica como de la francesa. Primeramente porque en ambos casos la crisis imperial derivó en otra constitucional trayendo consigo novedades políticas largamente maduradas por el pensamiento ilustrado, pero también porque ambas crisis conllevaron un serio reajuste de las propias políticas imperiales de las potencias europeas. En cuanto esta comenzó a agitarse en los dominios ingleses de América del norte, derivando en importantes enfrentamientos por el control del mar, la monarquía española

${ }^{16}$ Rafael García Pérez, Reforma y resistencia. Manuel de Flon y la intendencia de Puebla, México, Porrúa, 2000.

${ }^{17}$ Carlos Marichal, La bancarrota del virreinato, Nueva España y las finanzas del imperio español, 1780-1810, México, FCE, 1999;

18 Ernest Sánchez, "La mirada fiscal sobre el comercio interno: las alcabalas novohispanas", en María del Pilar Martínez, Ernest Sánchez y Matilde Souto (eds), La fiscalidad novohispana en el imperio español, México Instituto Mora, 2015.

19 John Tutino, Making a New World. Founding Capitalism In the Bajio and Spanish North América, Durham, Duke UP, 2011. 
se vio atrapada en la pinza formada por los imperios británico y francés, este último reinventado como un imperio republicano desde finales del siglo $\mathrm{XVIII}^{20}$.

Es importante tener presente este escenario porque fue en él donde el pensamiento que solemos identificar como Ilustración española tuvo su florecimiento. No es un dato que los estudios sobre ese movimiento intelectual en España suelan tener muy presente, pero es indudable que perfiló algunos aspectos interesantes del mismo, especialmente por lo que hacía a la consideración de España y su monarquía en el escenario europeo. En efecto, si el pensamiento ilustrado europeo no puede desligarse de la experiencia imperial y, sobre todo, de su reajuste en el siglo XVIII al hilo de los grandes conflictos entre las monarquías metropolitanas, otro tanto le sucedió al pensamiento español del setecientos.

Tanto para la mayor y más relevante parte de los pensadores ilustrados Jovellanos, Cadalso, Aguirre, Marchena, Cabarrús, entre otros - como luego para la historiografía contemporánea sobre la Ilustración española, América ha tenido una presencia ambivalente. Ha interesado, por una parte, como objeto rara vez sujeto - de civilización española y ha interesado también como banco de pruebas de esa misma civilización, sobre todo en la relación con lo que antes se llamaban salvajes y ahora otros ${ }^{21}$.

Visto en su complejidad imperial, sin embargo, el panorama cambia, pues la exigencia intelectual en este sentido fue doble. Por una parte hubo de dar respuesta al cuestionamiento ya mencionado de la relevancia de España y su imperio para la civilización europea y, por otro, tuvo que definir el objeto de su reflexión cuando se refería a la "nación española" en el contexto de una monarquía compleja que transmutaba entonces hacia una reformulación imperial.

Si el pensamiento europeo se mostró especialmente crítico con España y su cultura no fue únicamente por la ausencia de grandes nombres en ella, parangonables a los de los más señalados sabios europeos del momento. Fue, sobre todo, debido a su dimensión imperial. La historiografía ha tratado con la debida extensión la fabricación y difusión de la serie de estereotipos e ideas acerca del imperio español que componen la "leyenda negra" como un conjunto de críticas que tienen que ver con la conformación del imperio y con su funcionamiento. Buena parte de esa "leyenda" es fruto de la crítica ilustrada europea del setecientos, que retoma temas desarrollados en la competición imperial del siglo precedente ${ }^{22}$. En su conjunto, tienen que ver con una teoría

\footnotetext{
${ }^{20}$ José M. Portillo, "España en el mundo" en Manuel Chust (coord.), España. Crisis imperial e independencia 1808-1830, Madrid, Mapfre-Taurus, 2010.

${ }^{21}$ María José Villaverde y Gerardo López, Civilizados y salvajes. La mirada de los ilustrados sobre el mundo no europeo, Madrid, CEPC, 2015.

22 Eva Botella, "Debating Empires, Inventing Empires: British Territorial Claims Against the
} 
de los imperios que el pensamiento europeo trazó entonces y que, al igual que otras teorías sociales, se expuso de acuerdo a un criterio evolutivo. En ese panorama, el imperio español se antojaba primitivo e inadaptado a la modernidad puesto que se fundamentaba sobre las ideas de dominio militar e imposición religiosa. Los imperios modernos, los que podían asimilarse a la evolución social en sus estadios más desarrollados, eran los que se fundamentaban en el comercio y el trato ${ }^{23}$.

Con todo lo que de tramposo tenía el esquema según el cual dentro de una categoría, la primitiva, caían unos imperios y dentro de la otra, la moderna, otros, lo cierto es que el imperio español quedó de manera estereotipada más asimilado a una forma periclitada de imperio que a otra moderna y con futuro. Como entonces se dijo, en el imaginario ilustrado la monarquía de España quedaba a medio camino entre Turquía e Inglaterra.

Lo que nos interesa es señalar hasta qué punto ese cuestionamiento del encaje europeo de España debido justamente a su dimensión imperial produjo pensamiento al respecto entre los intelectuales españoles. Es bien conocida, pues la historiografía ha tratado regularmente la cuestión, que una parte significativa de los pensadores españoles de los años sesenta del siglo XVIII en adelante dedicaron una notable cantidad de páginas a rebatir la idea de la insignificancia española en términos de civilización europea. Juan Pablo Forner, José Cadalso, Juan Nuix entre otros muchos se refirieron expresamente a esa descalificación y a la necesidad de restablecer el nombre de la nación española en la república de las letras europeas ${ }^{24}$.

Al hacerlo, aquellos escritores comenzaron también a labrar una idea de "nación española" con la que identificarse. Como antes se dijo, debemos siempre tener presente que en todo momento estamos ante una identidad literaria de la nación española. Esto quiere decir que el sintagma no conllevaba entonces significación política de pretensión alguna de vincular a esa nación con el gobierno político. No obstante, desde dicho punto de vista, para la mayor parte de los intelectuales españoles europeos, ese sujeto de civilización tenía una significación exclusivamente metropolitana, no imperial. Así, por ejemplo, la ilustración jurídica jamás consideró relevante el derecho americano (ni el de la Recopilación de Indias ni menos derechos particulares americanos como los de cacicazgos, tratados con naciones indias independientes o el fuero de la provincia india de Tlaxcala, por ejemplo). Tampoco la geografía contaba con la parte colonial cuando se trataba de representar en mapas a «España» y menos las recopilaciones o bibliotecas de escritores hechas en la parte metropolitana

\footnotetext{
Spaniards in America. 1670-1714”, Journal for Early Modern Cultural Studies, 10, 1, 2010.

23 John Elliot, Imperios del mundo atlántico. España y Gran Bretaña en América, 1492-1830, Madrid, Taurus, 2006.

24 Javier Yagüe, «Defensa de España y conquista de América en el siglo XVIII», Dieciocho. Hispanic Enlightenment, 28, 2005.
} 
se sintieron en la necesidad de incluir adelantamientos ni glorias producidas en América $^{25}$.

En los contados casos en que «nación española» pudo tener significación política - como en los escasos proyectos constitucionales que comienzan a elaborarse a finales de la centuria - el espacio referido coincidía con el europeo, del mismo modo que la España que se presentaba ante Europa como un espacio de civilización era la que, como Cadalso dibujó, limitaba con los Pirineos, el Estrecho, el Mediterráneo y el Atlántico (lo que incluía a Portugal, pero no a América $)^{26}$. Es por ello importante seguir la pista de aquellas ideas de nación más relacionadas con un sujeto literario que político porque cuando sí se le comience a dar esa significación, el sujeto se tomará de ahí precisamente, de su significación como una identidad literaria y de civilización coincidente con la parte metropolitana de la monarquía.

Este distanciamiento de América respecto de la idea de nación en vísperas constitucionales se hace más interesante si contemplamos las cosas desde el momento de la crisis compleja que se abrió en 1808. En enero del año siguiente, como es bien sabido, la Junta Central haría una declaración insospechada según la cual los territorios y dominios españoles en América y Asia debían considerarse partes "esenciales" de la monarquía y, por lo tanto, debían ser llamados a la "representación nacional". Este decreto determinó a partir de entonces el sentido y la profundidad de la crisis española. Al convertirse no ya solamente en una crisis imperial y dinástica, sino también constitucional, el haber transformado tan radicalmente el lugar de América en el sistema imperial significó tener que idear respuestas constitucionales novedosas. Es sabido que no funcionarían y que no lo harían precisamente porque junto a la retórica de la igualdad acabó por superponerse la concepción imperial ${ }^{27}$.

Es por ello que se hace, como decía antes, más interesante aún prestar atención al modo en que el pensamiento ilustrado español concibió aquella "nación española" a la que tanto se refirió. En términos generales (y siempre con las debidas precauciones) podría convenirse en que los pensadores españoles de finales del siglo XVIII entendieron que la "nación" hacía referencia a la España que ellos habitaban, la peninsular. Se trataba de una asunción que no se somete siquiera a debate, quedando casi en anecdótico la aproximación que hiciera tempranamente Benito Ramón Feijoo sobre unos "españoles americanos". No es un asunto, el de la españolidad de los americanos, que entretuviera mucho a

\footnotetext{
${ }^{25}$ Carlos Garriga, "La Ilustración jurídica" en Marta Lorente y Jesús Vallejo, Manual de Historia del Derecho, Valencia, Tirant lo Blanc, 2012; Jesús Vallejo, "Geografía constitucional ilustrada". 2004.

${ }^{26}$ Ignacio Fernández Sarasola, Proyectos constitucionales en España (1786-1824), Madrid, CEPC,

${ }^{27}$ Marta Lorente y José M. Portillo (coords), El momento gaditano. La constitución en el orbe hispano, Madrid, Congreso de los Diputados, 2010.
}

Araucaria. Revista Iberoamericana de Filosofia, Politica, Humanidades y Relaciones Internacionales, año 20, ${ }^{\circ} 40$. Segundo semestre de 2018. Pp. 59-73. ISSN 1575-6823 e-ISSN 2340-2199 doi: 10.12795/araucaria.2018.i40.03 
la intelectualidad española, y menos cuando se trataba de ubicar a "España" en la república de las letras europeas.

Podemos observar esta aproximación en el tratamiento de materias y asuntos especialmente sensibles a su dimensión "nacional". Como se apuntó antes, así se puede apreciar en un asunto que sí se convirtió en un tópico preferido del pensamiento español en la segunda mitad del siglo, la determinación de un "derecho español" por oposición al "extranjero", que era el romano. Cuando Jovellanos u otros intelectuales se esforzaban en apuntar las fuentes de "nuestro" derecho enlistaban, casi sistemáticamente, cuerpos de derecho como el Fuero Juzgo, el Fuero Viejo de Castilla — precisamente rescatado entonces del olvido y del polvo_-, las Siete Partidas, el Ordenamiento de Alcalá, las Leyes de Toro, la Nueva Recopilación. A ello podrían añadirse cuerpos legales y fueros de otros reinos, sobre todo a medida que desde aquellos territorios se comience una labor de reivindicación propia. Lo que de ninguna manera entró en la nómina fue derecho americano. La razón no es únicamente porque la recopilación americana se entendiera como una manifestación más del derecho de Castilla, pues no hacía falta más que abrirla par ver el rastro de un derecho específicamente generado para aquella parte de la monarquía y, sobre todo, para ver el rastro también de un derecho perfectamente asimilable a los iura propria de otros espacios de la monarquía, como por ejemplo el que regulaba los cacicazgos o esa especie de fuero propio de la provincia india de Tlaxcala que se recoge en el libro $\mathrm{VI}^{28}$.

La parte imperial de la monarquía, sobre la que se estaba ensayando esa forma de gobierno pretoriana que antes mencionaba, tampoco hacía su aparición en la "geografía de España". Cadalso ni la mencionaba cuando trataba de explicar las dimensiones y extensión de la "nación española" en su defensa de la misma frente a la ironía de Montesquieu en sus Cartas persas. Tomás López, el iniciador en la segunda mitad del siglo de una geografía más sistemática y asequible pareció siempre tener clara la diferencia entre espacios dentro de los dominios del rey de España. Entre su producción se encuentra un muy interesante "Atlas portátil" en el que "España" es la península, incluyendo al "Reyno de Portugal", pero nada más. Nada más disfrutar de una beca en París para aprender el arte de hacer mapas, había realizado un Atlas geográfico de la América Septentrional y Meridional (1758), que dedicó a Fernando VI indicando que su objeto era trazar los confines de "las Provincias e Islas que nuestro Católico Monarca posee” en ella. Una cosa era lo que el monarca poseía y otra cosa era España.

Esa era la perspectiva habitual, que la parte imperial eran dominios que el rey "posee", mientras que la parte peninsular era la que se mostraba

28 José M. Portillo, Fuero Indio. La provincia india de Tlaxcala entre la monarquía imperial y la república nacional, 1780-1824, México, Instituto Mora-El Colegio de México, 2014.

Araucaria. Revista Iberoamericana de Filosofía, Política, Humanidades y Relaciones Internacionales, año 20, ${ }^{\circ} 40$. Segundo semestre de 2018. Pp. 59-73. ISSN 1575-6823 e-ISSN 2340-2199 doi: 10.12795/araucaria.2018.i40.03 
susceptible de ser defendida como "nación española". Ya sabemos que se decía en términos literarios, y en ellos es precisamente donde mejor podemos ver esa distinción de espacios. Siguiendo una línea marcada por otros elencos literarios, los realizados en el momento que nos ocupa siguieron ignorando casi sistemáticamente la producción española no peninsular. El monumento mejor elaborado de las glorias literarias españolas realizado en estas décadas, la Biblioteca española de Juan Sempere y Guarinos, está concebida expresamente en los términos nacionales que venimos indicando. Se trataba de una respuesta a la "indiferencia" con que las "naciones más cultas" veían a la española, una "Nación en que ha hecho tantos progresos el espíritu humano". Era necesario mostrar a Europa, por tanto, "una historia literaria de nuestra Nación, en la que se tratara filosóficamente, de las causas de los progresos de las Letras en España"29.

En vano se buscarán en los diferentes tomos que componen este magnífico prontuario nombres como los de José Alzate, José Celestino Mutis o Francisco Javier Clavijero. Este último caso es especialmente ilustrativo pues su compañero de religión, el también jesuita y expulso Juan Nuix, aparece en el elenco de Sempere. Ambos escribieron sobre América, pero Clavijero con mayor conocimiento de causa. Les diferenciaba, por tanto, solamente una connotación "de nación" que hacía al veracruzano invisible en una presentación de las glorias nacionales de la literatura española.

Es importante consignar que el pensamiento "español americano" no permaneció impasible ante esta ausencia. La reclamaron también en términos literarios y no olvidaron consignarla cuando recurrieron al rey como dispensador de gracias y mercedes a reclamar su legítimo lugar en el sistema de la monarquía ${ }^{30}$. La historiografía que ha analizado las querellas americanas de los años setenta y ochenta del setecientos ha señalado oportunamente la sensación difundida entre la clase criolla de estar siendo orillados en puestos y mercedes, pero también en términos de cultura. Juan José de Eguiara y Eguren, como ha sido también suficientemente señalado, ya había tenido la iniciativa de elaborar una Biblioteca mexicana que diera la réplica a la de Nicolás Antonio en lo que a la presencia americana se refería.

Estamos entonces ante una paradoja historiográfica en la que los españoles europeos reclamaban su consideración como parte esencial de la república de las letras europeas a la vez que ignoraban el aporte a esas glorias nacionales de los españoles americanos. Sin embargo, estos últimos no dejaron, a su vez, de manifestar su derecho a ser considerados parte de esa misma «nación» española que se vindicaba ante Europa. Cuando Eguiara y Eguren se indignaba ante la

29 Juan Sempere, ensayo de una biblioteca de los mejores escritores del reinado de Carlos III, Madrid, Imprenta Real, 1785, discurso preliminar.

${ }^{30}$ Carlos Garriga, "La politización de la América criolla. (En torno a la Representación mexicana de 1771)", en Pedro Yanzi Ferreira (comp.), XVIII Congreso del Instituto Internacional de Historia del Derecho Indiano, Córdoba, Universidad Nacional de Córdoba, 2016. 
ignorancia de los eruditos españoles acerca de la literatura americana, cuando los médicos criollos defendían la ciencia indígena como propia o cuando la primera arqueología mexicana mostraba la magnificencia de ciudades prehispánicas, estaba la Ilustración americana intentando conectar con la «nación» literaria española ${ }^{31}$.

Como antes se dijo, entiendo que todo ello es relevante y debe seguir formando parte de nuestros intereses historiográficos puesto que no debemos perder de vista que en la crisis de la monarquía abierta en 1808 todo ello será de la máxima relevancia. Dar entrada en el ámbito de la "nación española" como "parte esencial" de la monarquía a las provincias americanas iba literalmente en el sentido opuesto al imaginario que sobre nación e imperio había generado el pensamiento peninsular español de finales del siglo XVIII. Como no podía ser de otra manera esa costumbre intelectual, por decirlo así, debía pesar y lo hizo a la hora de pasar de la retórica de la igualdad a la práctica constitucional, que definitivamente no pudo sino reintroducir aquella división de espacios y generar una suerte de nación imperial.

31 Miruna Achim, Lagartijas medicinales: remedios americanos y debates ilustrados, México, UAM-Conaculta, 2008 . 


\section{Referencias bibliográficas:}

Achim Miruna, Lagartijas medicinales: remedios americanos y debates ilustrados, México, UAM-Conaculta, 2008.

Álvarez Barrientos Joaquín François Lope e Inmaculada Urzainqui, La república de las letras en la España del siglo XVIII, Madrid, CSIC, 1995

Bell David A., The First Total War. Napoleon's Europe and the Birth of Warfare as we know it, Nueva York, Mariner Books, 2008.

Botella Eva, »Debating Empires, Inventing Empires: British Territorial Claims Against the Spaniards in America. 1670-1714“, Journal for Early Modern Cultural Studies, 10, 1, 2010.

Cañizares-Esguerra Jorge, Cómo escribir la historia del Nuevo Mundo. Historiografías, epistemologías e identidades en el mundo del Atlántico del siglo XVIII, México, FCE, 2007.

Compagnon Antoine, Los antimodernos, Barcelona, Acantilado, 2007.

Conde Esteban, Medioevo ilustrado. La edición erudita del Ordenamiento de Alcalá (1774), Sevilla, Secretariado de Publicaciones de la Universidad de Sevilla, 1998.

Delgado Josep M., Dinámicas imperiales. España, América y Europa en el cambio institucional del sistema colonial español, Barcelona, Bellaterra, 2007.

Elliot John, Imperios del mundo atlántico. España y Gran Bretaña en América, 1492-1830, Madrid, Taurus, 2006.

Fernández Sarasola Ignacio, Proyectos constitucionales en España (17861824), Madrid, CEPC, 2004.

Ferrone Vicenzo y RocheDaniel, L'Illuminismo. Dizionario storico, Roma, Laterza, 1998.

García Pérez Rafael, Reforma y resistencia. Manuel de Flon y la intendencia de Puebla, México, Porrúa, 2000.

Garriga Carlos, «La Ilustración jurídica» en Marta Lorente y Jesús Vallejo, Manual de Historia del Derecho, Valencia, Tirant lo Blanc, 2012.

Garriga Carlos, «La politización de la América criolla. (En torno a la Representación mexicana de 1771)», en Pedro Yanzi Ferreira (comp.), XVIII Congreso del Instituto Internacional de Historia del Derecho Indiano, Córdoba, Universidad Nacional de Córdoba, 2016.

Gerbi Antonello, La disputa del Nuevo Mundo. Historia de una polémica, 1750-1900, México, FCE, 1993. 
Jüttner Siegfried, "Archive der Nationenbildung im Namen Europas. Die Presse im Spanien der Aufklärung als Medium nationaler Regeneration”, en Siegfried Jüttner, Die Konstituierung eines Kultur- und Kommunikationsraumes Europa im Wandel der Medienlandschaft des 18. Jahrhunderts, Berlín, Peter Lang, 2008.

Kuethe Alan y Adrien Keneth J. (eds), The Spanish Atlantic World in the eighteenth Century : War and the Bourbon Reforms, 1713-1796, Cambridge, Cambridge UP, 2014.

Lorente Marta y Portillo José M. (coords), El momento gaditano. La constitución en el orbe hispano, Madrid, Congreso de los Diputados, 2010.

Maliks Reidar, Kant's Politics in Context, Oxford, OUP, 2014.

Marichal Carlos, La bancarrota del virreinato, Nueva España y las finanzas del imperio español, 1780-1810, México, FCE, 1999.

Panasek Brad y Wellmon Chad "Enlightenment, Some Assembly Required" en David T. Gies y Cynthia Wall (eds), The Eighteenth Century. Global Networks of Enlightenment, Charlotesville, University of Virginia Press, 2018.

Portillo José M., «España en el mundo» en Manuel Chust (coord.), España. Crisis imperial e independencia 1808-1830, Madrid, Mapfre-Taurus, 2010.

Portillo José M., Fuero Indio. La provincia india de Tlaxcala entre la monarquía imperial y la república nacional, 1780-1824, México, Instituto Mora-El Colegio de México, 2014.

Sánchez Ernest, "La mirada fiscal sobre el comercio interno: las alcabalas novohispanas", en María del Pilar Martínez, Ernest Sánchez y Matilde Souto (eds), La fiscalidad novohispana en el imperio español, México Instituto Mora, 2015.

Sánchez-Blanco Francisco, Europa y el pensamiento español del siglo XVIII, Madrid, Alianza, 1991.

Sempere Juan, ensayo de una biblioteca de los mejores escritores del reinado de Carlos III, Madrid, Imprenta Real, 1785.

Stein Stanley J. y Stein Barbara, Apogee of empire : Spain and New Spain in the age of Charles III, 1759-1789, Baltimore, Johns Hopkins UP, 2003.

Sternhell Zeev, The Anti-Enlightenment Tradition, New HAven, Yale UP, 2010 Tavárez José Fidel, "La invención de un imperio comercial hispano, 17401765", Magallánica, 2/3, 2015.

Torres Rafael, El precio de la guerra. El estado fiscal-militar de Carlos III (1779-1783), Madrid, Marcial Pons, 2013.

Tutino John, Making a New World. Founding Capitalism In the Bajio and Spanish North América, Durham, Duke UP, 2011. 
Vallejo Jesús, "De sagrado arcano a constitución esencial. Identificación histórica del derecho patrio" en Pablo Fernández Albaladejo (ed.), Los Borbones. Dinastía y memoria de nación en la España del siglo XVIII, Madrid, Marcial Pons - Casa de Velázquez, 2001.

Vallejo Jesús, "El Fuero Real bajo las luces, o las sombras de la edición de 1781", en Initium. Revista Catalana d'Història del Dret, 1, 1996.

Villaverde María José y López Gerardo, Civilizados y salvajes. La mirada de los ilustrados sobre el mundo no europeo, Madrid, CEPC, 2015.

Yagüe Javier, «Defensa de España y conquista de América en el siglo XVIII», Dieciocho. Hispanic Enlightenment, 28, 2005. 
